\title{
PEMBUATAN KEKASARAN PERMUKAAN MATERIAL ST 37 TERHADAP KECEPATAN PEMAKANAN PADA MILLING MACHINE
}

\author{
${ }^{(1)}$ Sugiyanto ${ }^{2}$ Yogi Prabowo \\ ${ }^{(1,2)}$ Prodi Teknik Mesin Universitas Surakarta \\ ${ }^{(1)}$ Email: Sugiyantoputro@yahoo.co.id \\ Jl. Raya Palur Km.5 Palur Karanganyar
}

\begin{abstract}
One of the ideal geometric characteristics of a component is a smooth or rough surface. In practice it is not possible to obtain a component with a smooth / rough surface. This is due to several factors, such as the human factor (operator) and the factors of the machines used to make it. However, with technological advancements the growing apparatus capable of forming surface components with a high degree of fineness / roughness, according to the standard measures applicable in metrology, is advanced by geometric measurement experts through research experience.

Fineness level / roughness of a surface is very important role in the planning of a machine components, especially concerning the problem of lubrication friction, wear and tear, resistance to fatigue and so on. Therefore, in the planning and manufacture must be considered first about which machine equipment should be used to make it and how much the cost must be incurred. In order for the process of manufacture there is no significant deviation, then the characteristics of this surface should be understood by the planner even more by the operator. Communication of surface characteristics is usually done in engineering drawings. But to explain perfectly about the characteristics of a surface seems difficult.

The research method is started by preparing instrument that is Milling Machine which is used to make surface roughness and Surface Roughness Tester is done 3 times test with variable speed of food which is different equal to 7,3; 13; $24.5 \mathrm{~mm} /$ put. With a speed of $102 \mathrm{rpm} \mathrm{Rpm}$, and a depth of 0.4 . Next determine the material roughness level with Surface Roughness Tester. After all done will get the data test results, followed by analysis and discussion so that will get final conclusion.

From the research results obtained the following results: there is a difference in the level of roughness in each material with different feeding speed. The feed rate of $7.3 \mathrm{~mm} /$ put yielded $0.64 \mu, 13 \mathrm{~mm} / \mathrm{put}$ roughness generated $1.32 \mu, 24.5 \mathrm{~mm} /$ put yielded $3.77 \mu$. The process of measuring the roughness of the material with the speed of feeding is slower, the smoother the surface roughness, the faster the speed of the feeding the more rough. The range of syrup result is also influenced by the speed of the food. The faster the movement of the range range the wider the surface roughness is the opposite.
\end{abstract}

Keywords: speed of food, milling machine, roughness, material ST 37

\section{PENDAHULUAN}

Salah satu karakteristik geometris yang ideal dari suatu komponen adalah permukaan yang halus atau kasar. Dalam prakteknya memang tidak mungkin untuk mendapatkan suatu komponen dengan permukaan yang betul-betul halus/kasar. Hal ini disebabkan oleh beberapa faktor, misalnya faktor manusia (operator) dan faktor-faktor dari mesin-mesin yang digunakan untuk membuatnya. Akan tetapi, dengan kemajuan teknologi semakin berkembang peralatan yang mampu membentuk permukaan komponen dengan tingkat kehalusan/kasar yang cukup tinggi, menurut standar ukuran yang berlaku dalam metrologi, yang dikemukakan oleh para ahli pengukuran geometris benda melalui pengalaman penelitian.

Tingkat kehalusan/kekasaran suatu permukaan memang peranan yang sangat penting dalam perencanaan suatu komponen mesin khususnya yang menyangkut masalah gesekan pelumasan, keausan, tahanan terhadap kelelahan dan 
sebagainya. Karenaitu, dalam perencanaan dan pembuatannya harus dipertimbangkan terlebih dulu mengenai peralatan mesin yang mana harus digunakan untuk membuatnya serta berapa ongkos yang harus dikeluarkan. Agar proses pembuatannya tidak terjadi penyimpangan yang berarti, maka karakteristik permukaan ini harus dapat dipahami oleh perencana lebih-lebih lagi oleh operator.

Komunikasi karakteristik permukaan biasanya dilakukan dalam gambar teknik. Namun untuk menjelaskan secara sempurna mengenai karakteristik suatu permukaan nampaknya sulit.

\section{LANDASAN TEORI}

\section{Kajian tentang Kekasaran Permukaan}

Permukaan adalah batas yang memisahkan benda padat dengan sekelilingnya. Karakteristik suatu permukaan memegang peranan penting dalam pemberian adhesive sebagai media penyambung. Proses penyambungan secara lap joint kedua penampang permukaan komposit memerlukanan kekasaran. Pengukuran kekasaran menggunakan alat pengukur keasaran (Surface Roughness Tester).

Dhiah Purbosari (2010), tingkat kekasaran permukaan terkecil sebelum awal waktu pemberian pendingin pada proses pemesinan $\mathrm{CNC}$ milling ZK 7040 terjadi pada feed rate $0,11 \mathrm{~mm} / \mathrm{rev}$ dan awal waktu pemberian pendingin 10 menit yaitu sebesar $1,616 \mu \mathrm{m}$, sedangkan tingkat kekasaran paling besar terjadi pada feed rate $0,15 \mathrm{~mm} / \mathrm{rev}$ dan awal waktupemberian pendingin 20 menit yaitu sebesar 3,603 $\mu$ m.angka kekasaran 3,85 $\mu \mathrm{m}, 3,73 \mu \mathrm{m}, 3,40 \mu \mathrm{m}, 3,20 \mu \mathrm{m}$.

P. Chockalingam, (2012), Penelitian ini membahas pengaruh kondisi pendingin yang berbeda pada baja tahan karat AISI 304. Metode pendinginan yang digunakan dalam penelitian ini adalah banjir minyak sintetis, emulsi berbasis air, dan udara dingin tekan. Kekuatan pemotong dan kekasaran permukaan dipelajari dan penutup alat pengaman diamati. Pada penelitian ini, perbandingan antara efek pendingin yang berbeda dengan baja tahan karat AISI 304 dilakukan dan hasil dari penelitian ini dapat memberikan informasi yang sangat berguna di bidang manufaktur. Hasil percobaan menunjukkan bahwa emulsi berbasis air memberikan permukaan akhir yang lebih baik dan gaya potong yang lebih rendah diikuti oleh minyak sintetis dan udara dingin tekan. Kondisi pendinginan yang berbeda memerlukan parameter yang berbeda untuk mendapatkan kekasaran permukaan bawah dan gaya potong.

Deepak Kumar (2012), Permukaan kekasaran adalah respon output penting dalam produksi berkenaan dengan kualitas dan kuantitas masing-masing. Proses penggilingan mesin abrasif banyak digunakan untuk mencapai toleransi yang lebih dekat dengan permukaan akhir yang lebih baik. Pekerjaan ini baja kerja panas AISI H11 digunakan untuk menyelidiki peran lingkungan kerja yang berbeda (pendinginan kering, pendinginan basah dan gas tekan) dan parameter proses (laju umpan, kedalaman kecepatan potong dan roda) pada kekasaran permukaan. Telah diamati bahwa di bawah lingkungan pendinginan basah, penurunan laju umpan, kedalaman pemotongan dan kenaikan kecepatan roda menghasilkan peningkatan kualitas permukaan yang signifikan.

Kekasaran permukaan dapat diwakilkan kedalam sebuah grafik yang memiliki bentuk yang sama dengan profil yang diukur. Grafik tersebut merupakan pembesaran dari kekasaran permukaan pada profil tersebut. Dari grafik yang didapatkan tersebut, dapat dicari beberapa parameter-parameterguna menganalisa dan mengidentifikasi konfigurasi suatu permukaan

Permukaan adalah suatu batas yang memisahkan benda padat dengan sekitarnya. Profil atau bentuk yang dikaitkan dengan istilah permukaan mempunyai arti tersendiri yaitu garis hasil pemotongan secara normal atau serong 
dari suatu penampang permukaan. Kekasaran terdiri dari ketidakteraturan tekstur permukaan benda, yang pada umumnya mencakup ketidakteraturan yang diakibatkan oleh perlakuan selama proses produksi.

Tekstur permukaan adalah pola dari permukaan yang menyimpang dari suatu permukaan nominal. Penyimpangan mungkin atau berulang yang diakibatkan oleh kekasaran, waviness, lay, dan flaws. Kekasaran permukaan (surface roughness) dibedakan menjadi dua, yaitu:

a) Ideal Surface Roughness Ideal surface roughness

Kekasaran ideal (terbaik) yang bisa dicapai dalam suatu proses permesinan dengan kondisi ideal. Faktor-faktor yang mempengaruhi kekasaran ideal di antaranya:

- Getaran yang terjadi pada mesin.

- Ketidaktepatan gerakan bagian bagian mesin.

- Ketidakteraturan feed mechanism.

- Adanya cacat pada material.

- Gesekan antara chip dan material

b) Natural Surface Roughness Natural surface roughness

Kekasaran alamiah yang terbentuk dalam proses permesinan karena adanya berbagai faktor yang mempengaruhi proses permesinan tersebut. Parameter kekasaran permukaan sebelum jauh melangkah ke parameter kekasaran perlu diketahui terlebih dahulu tentang profil yang penting seperti yang terlihat pada Gambar 1.1. berikut ini :

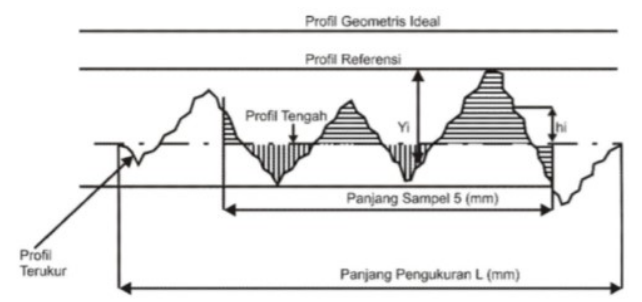

Gambar 1. Suatu kekasaran permukaaan

Profil kekasaran permukaan terdiri dari:

a. Profil geometrik ideal ialah profil pemukaan yang sempurna dapat berupa garislurus, lengkung atau busur. b. Profil terukur (measured profil), merupakan profil permukaan terukur.

c. Profil referensi adalah profil yang digunakan sebagai acuan untukmenganalisa ketidakteraturan konfigurasi permukaan.

d. Profil akar/alas yaitu profil referensi yang digeserkan ke bawah sehingga menyinggung titik terendah profil terukur.

e. Profil tengah adalah profil yang digeserkan ke bawah sedemikian rupa sehingga jumlah luas bagi daerah-daerah diatas profil tengah sampai profil terukur adalah sama dengan jumlah luas daerah-daerah di bawah profil tengah sampai ke profil terukur.

Berdasarkan profil-profil di Gambar 1. di atas, dapat didefinisikan beberapa parameter permukaan, yaitu yang berhubungan dengan dimensi pada arah tegak dan arah memanjang. Untuk dimensi arah tegak dikenal beberapa parameter, yaitu:

a. Kekasaran total (peak to valley height/total height $), \operatorname{Rt}(\mu \mathrm{m})$ adalah jarak antara profil referensi dengan profil alas.

b. Kekasaran perataan (depth of surface smoothness/peak to mean line), $\mathrm{Rp}(\mu \mathrm{m})$ adalah jarak rata-rata antara profil referensi dengan profil terukur.

c. Kekasaran rata-rata aritmetik (mean roughness index/center line average, $C L A), \quad \operatorname{Ra}(\mu \mathrm{m})$ adalah harga rata-rata aritmetik dibagi harga absolutnya jarak antara profil terukur dengan profil tengah.

\section{Tinjauan Tentang Milling Machine}

Proses pemesinan frais adalah proses penyayatan benda kerja dengan alat potong dengan mata potong jamak yang berputar. Proses penyayatan dengan gigi potong yang banyak yang mengitari pahat ini bisa menghasilkan proses pemesinan lebih cepat. Permukaan yang disayat bisa berbentuk datar, menyudut, atau melengkung. Permukaan benda kerja bisa juga berbentuk kombinasi dari beberapa bentuk. Mesinyang digunakan untuk memegang benda kerja, memutar pahat, dan penyayatannya disebut mesin frais (Milling Machine). 


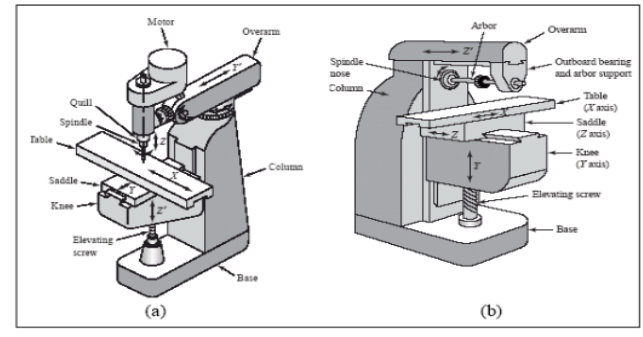

Gambar 2.Milling Machine

Mesin frais yang digunakan dalam proses pemesinan ada tiga jenis, yaitu :

1. Column and knee milling machines

2. Bed type milling machines

3. Special purposes

Mesin jenis column and knee dibuat dalam bentuk mesin frais vertikal dan horisontal. Kemampuan melakukan berbagai jenis pemesinan adalah keuntungan utama pada mesin jenis ini. Pada dasarnya pada mesin jenis ini meja (bed), sadel, dan lutut (knee) dapat digerakkan. Beberapa asesoris seperti cekam, meja putar, kepala pembagi menambah kemampuan dari mesin frais jenis ini. Walaupun demikian mesin ini memiliki kekurangan dalam hal kekakuan dan kekuatan penyayatannya. Mesin frais tipe bed (bed type) memiliki produktivitas yang lebih tinggi dari pada jenis mesin frais yang pertama.

Kekakuan mesin yang baik, serta tenaga mesin yang biasanya relatif besar, menjadikan mesin ini banyak digunakan pada perusahaan manufaktur. Mesin frais pada saat ini telah banyak yang dilengkapi dengan pengendali CNC untuk meningkatkan produktivitas dan fleksibilitasnya. Jika menggunakan mesin produksi CNC maka waktu produksi bisa dipersingkat, bentuk benda kerja sangat bervariasi.

Produk pemesinan di industri pemesinan semakin kompleks, maka mesin frais jenis baru dengan bentuk yang tidak biasa telah dibuat. Mesin frais tipe khusus ini, biasanya digunakan untuk keperluan mengerjakan satu jenis penyayatan dengan produktivitas/duplikasi yang sangat tinggi. Mesin tersebut misalnya mesin frais profil, mesin frais dengan spindel ganda (dua, tiga, sampai lima spindel), dan mesin frais planer.

Penggunaan mesin frais khusus, maka potensi produktifitas mesin sangat tinggi, sehingga ongkos produksi menjadi rendah, karena mesin jenis ini tidak memerlukan seting yang rumit. Selain mesin frais manual, pada saat ini telah dibuat mesin frais dengan jenis yang sama dengan mesin konvensional tetapi menggunakan kendali CNC (Computer Numerically Controlled). Bantuan kendali $\mathrm{CNC}$, maka mesin frais menjadi sangat fleksibel dalam mengerjakan berbagai bentuk benda kerja, efisien waktu dan biaya yang diperlukan dan produk yang dihasilkan memiliki ketelitian tinggi.

\section{Tinjauan Tentang Material ST 37}

Baja adalah seluruh macam besi yang dengan tidak dikerjakan terlebih dahulu lagi, sudah dapat di tempa. Baja adalah bahan yang serba kesamaannya (homogenitasnya) tinggi, terdiri terutama dari Fe dalam bentuk kristal dan $\mathrm{C}$. Pembuatannya dilakukan sebagai pembersihan dalam temperatur yang tinggi dari besi mentah yang di dapat dari proses dapur tinggi. Baja adalah besi mentah tidak dapat ditempa (Robert L. Mott, 2004).

Sifat-sifat umum dari baja :

a. Keteguhan (solidity) artinya mempunyai ketahanan terhadap tarikan, tekanan atau lentur.

b. Elastisitas (elasticity) artinya kemampuan atau kesanggupan untuk dalam batas- batas pembebanan tertentu, sesudahnya pembebanan ditiadakan kembali kepada bentuk semula.

c. Kekenyalan/keliatan (tenacity) artinya kemampuan atau kesanggupan untuk dapat menerima perubahan bentuk yang besar tanpa menderita kerugiankerugian berupa cacat atau kerusakan yang terlihat dari luar dan dalam untuk jangka waktu pendek.

d. Kemungkinan ditempa (malleability) sifat dalam keadaan merah pijar 
menjadi lembek dan plastis sehingga dapat dirubah bentuknya.

e. Kemungkinan dilas (weklability) artinya sifat dalam keadaan panas dapat digabungkan satu sama lain dengan memakai atau tidak memakai bahan tambahan, tanpa merugikan sifat-sifat keteguhannya.

f. Kekerasan (hardness) kekuatan melawan terhadap masuknya benda lain

Menurut kekuatannya terdapat beberapa jenis baja, diantaranya: ST 37, ST 42, ST 50, dan seterusnya. Standart DIN (Jerman) St X X kekuatan dalam $\mathrm{kg} / \mathrm{mm} 2$ steel (baja). Contoh : ST37: baja dengan kekuatan $37 \mathrm{~kg} / \mathrm{mm}^{2}$.

Baja ST 37 banyak digunakan untuk kontruksi umum karena mempunyai sifat mampu las dan kepekan terhadap retaklas. Baja ST 37 adalah berarti baja yang mempunyaikekuatan tarik antara37 $\mathrm{kg} / \mathrm{mm}^{2}$ sampai $45 \mathrm{~kg} / \mathrm{mm}^{2}$. Kekuatan tarik ini adalah maksimum kemampuan sebelum material mengalami patah. Kekuatan tarik yield $(\sigma y)$ baja harganya dibawah kekuatan tarik maksimum. Baja pada batas kemampuan yield merupakan titik awal dimana sifatnya mulai berubah dari elastis menjadi plastis, Perubahan sifat material baja tersebut pada kondisi tertentusangat membahayakan fungsi konstruksi mesin.

Kemungkinan terburuk konstruksi mesin akan mengalami kerusakan ringan sampai serius. Baja St 37 dijelaskan secara umum merupakan baja karbon rendah, disebut juga baja lunak, banyak sekali digunakan untuk pembuatan baja batangan, tangki, perkapalan, jembatan, menara, pesawat angkat dan dalam permesinan.

\section{METODE PENELITIAN}

\section{A. Alat Penelitian}

Peralatan yang digunakan dalam penelitian ini adalah :
a. Milling Machine
b. Surface Roughness Tester Surfome 120 $A$ milik Laboratorium UNS
c. Mesin Polles

d. Mesin Gerinda Potong

\section{B. Bahan Penelitian}

Material uji yang digunakan Material baja ST 37

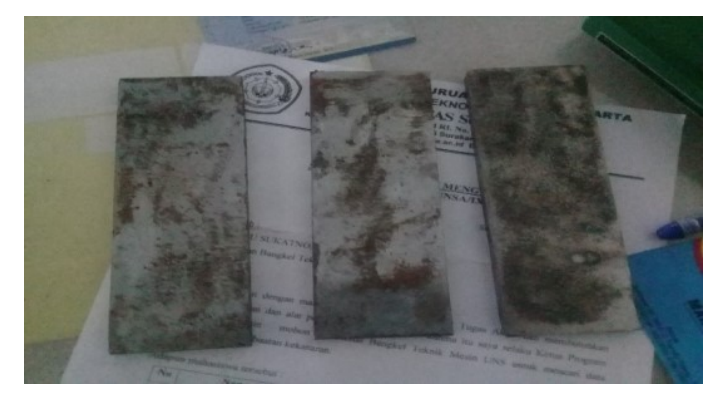

Gambar 3. Baja ST 37

\section{HASIL DAN PEMBAHASAN}

\section{A. Hasil Penelitian}

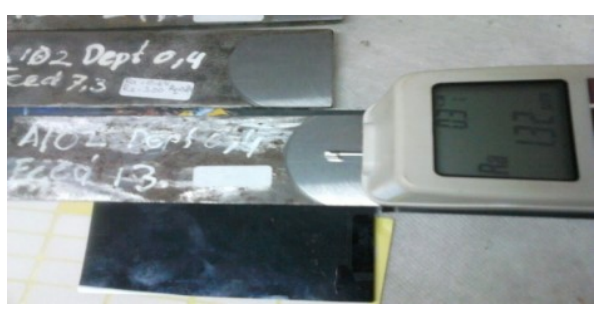

Gambar 4. Hasil Kekasaran

Tabel. 1. Hasil pengujian kekasaran material ST 37

\begin{tabular}{|c|c|c|c|c|}
\hline No & Jenis Material & Putaran Mesin & Kecepatan Makan & $\begin{array}{c}\text { Hasil Uji Rata -rata } \\
\text { Kekasaran }(\mu \mathrm{m})\end{array}$ \\
\hline \multirow{2}{*}{1} & \multirow{3}{*}{ ST 37 } & \multirow{2}{*}{$102 \mathrm{~mm}$} & $7,3 \mathrm{~mm} / \mathrm{put}$ & 0,64 \\
\cline { 4 - 5 } & & & $13 \mathrm{~mm} / \mathrm{put}$ & 1,32 \\
\cline { 4 - 5 } & & $24,5 \mathrm{~mm} / \mathrm{put}$ & 3,77 \\
\hline
\end{tabular}

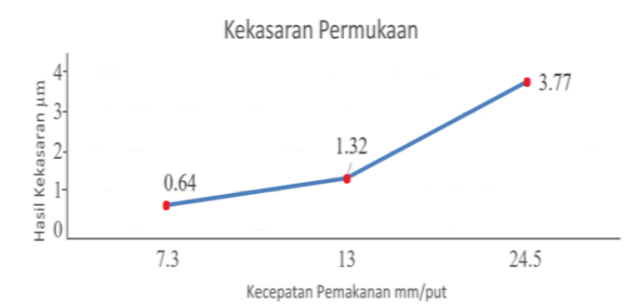

Gambar 5. Grafik Kekasaran

\section{B. Pembahasan}

Grafik kekasaran diatas menunjukkan bahwa, tingkat kekasaran permukaan suatu benda, kecepatan pemakanan merupakan faktor yang menyebabkan nilai angka kekasaran $(\mathrm{Ra})$. 
Kecepatan pemakanan dengan 7,3 mm/put dihasilkan kekasaran $0,64 \mu, 13 \mathrm{~mm} /$ put dihasilkan 1,32 $\mu, 24,5 \mathrm{~mm} /$ put dihasilkan $3,77 \mu$. Hasil kecepatan pemakanan nilai angka kekasaran $(\mathrm{Ra})$ paling tinggi pada 24,5 $\mathrm{mm} /$ put, sedangkan nilai kekasaran paling rendah pada kecepatan pemakanan $7,3 \mathrm{~mm} /$ put.

Proses pengukuran kekasaran pada material dengan kecepatan pemakanan semakin lambat, nilai kekasaran permukaan semakin halus, sedangkan semakin cepat kecepatan pemakanan semakin kasar. Hal ini yang menyebabkan nilai kekasaran permukaan suatu material berbeda. Perbedaan ini disebabkan jarak kisar sayatan antara kisar sayatan yang lain, akibat feeding speed pada pisau berbeda. Hal ini juga dipengaruhi oleh kecepatan pemakanan. Semakin cepat gerak pemakanan jarak kisar semakin hasil kekasaran permukaan semakin lebar dan sebaliknya.

\section{KESIMPULAN}

Dari hasil tersebut disimpulkan :

1. Tingkat kekasaran permukaan suatu benda, kecepatan pemakanan merupakan faktor yang menyebabkan nilai angka kekasaran (Ra). Kecepatan pemakanan dengan $7,3 \mathrm{~mm} / \mathrm{put}$ dihasilkan kekasaran $0,64 \mu \mathrm{m}, 13$ $\mathrm{mm} /$ put dihasilkan 1,32 $\mu \mathrm{m}, \quad 24,5$

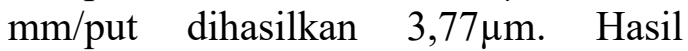
kecepatan pemakanan nilai angka kekasaran $(\mathrm{Ra})$ paling tinggi pada 24,5 $\mathrm{mm} /$ put, sedangkan nilai kekasaran paling rendah pada kecepatan pemakanan 7,3 mm/put.

2. Kecepatan pemakanan semakin lambat, nilai kekasaran permukaan semakin halus, sedangkan semakin cepat kecepatan pemakanan semakin kasar. Hal ini dibuktikan adanya perbedaan jarak kisar sayatan antara yang satu dengan kisar sayatan lain.
Daniel, 2012. "Surface Analysis of Machined Fiber Glass Composite Material', Recent Researches in Manufacturing Engineering, Université de Franche-Comté.

Deepak K (2012), Effect of Process Parameters On Surface Roughness During Grinding Of Hot Work Steel AISI H11 Under Dry, Wet And Compressed Gas Environment, Department of Mechanical Engineering, M.Tech. Scholar, DAVIET Jalandhar, India

Dhiah P, 2010, “ Karakterisasi Tingkat

Kekasaran Permukaan Baja St 40 Hasil Pemesinan CNC Milling Zk 7040 Efek Dari Kecepatan Pemakanan (Feed Rate) dan Awal Waktu Pemberian Pendingin," Tugas Akhir, UNS

Dwi Rahdianta (2010), Pengantar Mesin Bubut dan Frais, Universitas Negeri Yogyakarta,

P. Chockalingam, Lee Hong Wee (2012),

"Surface Roughness and Tool Wear Study on Milling of AISI 304 Stainless Steel Using Different Cooling Conditions," Faculty of Engineering and Technology, Multimedia University, Melaka, Malaysia.

Robert L. Mott, (2004), Elemen-elemen Mesin dalam Perancangan Mekanis, University of Dayton. Syed2012, Machinability Of Glass Fiber Reinforced Plastic (GFRP) Composite Materials, International Journal of Materials Processing Technology, African.

\section{DAFTAR PUSTAKA}

